\title{
Molecular Docking Study of Conformational Polymorph: Building Block of Crystal Chemistry
}

\author{
Rashmi Dubey, ${ }^{1,2}$ Ashish Kumar Tewari, ${ }^{1}$ Ved Prakash Singh, ${ }^{1}$ Praveen Singh, \\ Jawahar Singh Dangi, ${ }^{2}$ Carmen Puerta, ${ }^{3}$ Pedro Valerga, ${ }^{3}$ and Rajni Kant ${ }^{4}$ \\ ${ }^{1}$ Department of Chemistry, Faculty of Science, Banaras Hindu University, Varanasi 221005, India \\ ${ }^{2}$ Institute of Pharmaceutical Sciences, Guru Ghasidas Vishwavidyalya (A Central University), Bilaspur, Chhattisgarh 495009, India \\ ${ }^{3}$ Departamento de Ciencia de los Materiales e Ingenieria Metalurgica, Facultad de Ciencias, Campus Universitario del Rio San Pedro, \\ 11510 Puerto Real, Spain \\ ${ }^{4}$ Department of Physics, Jammu University, Jammu 180016, India
}

Correspondence should be addressed to Rashmi Dubey; rashmibhu@gmail.com and Ashish Kumar Tewari; tashish2002@yahoo.com

Received 18 August 2013; Accepted 15 September 2013

Academic Editors: E. Kryachko and I. Shibata

Copyright (C) 2013 Rashmi Dubey et al. This is an open access article distributed under the Creative Commons Attribution License, which permits unrestricted use, distribution, and reproduction in any medium, provided the original work is properly cited.

Two conformational polymorphs of novel 2-[2-(3-cyano-4,6-dimethyl-2-oxo-2H-pyridin-1-yl)-ethoxy]-4,6-dimethyl nicotinonitrile have been developed. The crystal structure of both polymorphs (1a and $\mathbf{1 b}$ ) seems to be stabilized by weak interactions. A difference was observed in the packing of both polymorphs. Polymorph $\mathbf{l b}$ has a better binding affinity with the cyclooxygenase (COX-2) receptor than the standard (Nimesulide).

\section{Introduction}

Polymorphism "Supramolecular isomerism" is pertinent to supramolecular chemistry, and crystal engineering in the same way as isomerization is pertinent to organic molecules. In the simplest way, polymorphism is the ability of molecules to produce more than one crystal structure $[1,2]$, resulted from interplay of kinetic and thermodynamic parameters [3]. The complexities of the organic solid state and especially the differences of intermolecular forces influence crystal packing [4]. Conformational polymorphism will always be a possibility for molecules that have multiple conformational isomers accessible energetically: every different conformation is a different molecular shape and can, in principle, form its own crystalline polymorph (or polymorphs) [5]. Because of the variation in crystallization environment (e.g., temperature, solvent, using of additives, and concentration), the same molecules can pack differently and form different crystal lattices or polymorphs [6-8]. As a result, the physical, chemical, and mechanical properties of the crystals can be dramatically affected. Nicotinonitrile-based crystals are highly influenced by $\sigma$ and $\pi$ cooperative effects [9]. Self-assemblies of these derivatives are governed by various weak interactions [1020]. The presence of various weak interactions leads to the development of polymorphism in compounds [21-25]. Polymorphism in organic and inorganic solids can be of crucial importance in the drug design and pharmaceutical industries due to its regulatory action [26-28]. Earlier we had studied weak interactions and its polymorphism in 1,3bis(4,6-dimethyl-1H-nicotinonitrile-1-yl)1,3-dioxy propane, which was symmetrical dimer [29]. This current study is focused on the pharmaceutical property of dissymmetrical molecule, 2-[2-(3-cyano-4,6-dimethyl-2-oxo-2H-pyridin-1yl)-ethoxy]-4,6-dimethyl nicotinonitrile, and its polymorphs (1a and $\mathbf{1 b}$ ).

\section{Experimental}

2.1. Synthesis of 2-[2-(3-Cyano-4,6-dimethyl-2-oxo-2H-pyridin-1-yl)-ethoxy]-4,6-dimethyl-nicotinonitrile. To a solution of 3-cyano-4, 6-dimethyl-2-oxo-nicotinonitrile (3g, 0.02 mole) in $10 \mathrm{~mL}$ dry DMF, potassium carbonate $(2.68 \mathrm{~g}$, 0.02 mole) was added and the mixture was stirred for $2 \mathrm{~h}$. 
TABLE 1: Crystal data and structure refinement for polymorphs $\mathbf{1 a}$ and $\mathbf{1 b}$.

\begin{tabular}{|c|c|c|}
\hline Compound & la & $\mathbf{l b}$ \\
\hline Empirical formula & $\mathrm{C}_{18} \mathrm{H}_{18} \mathrm{~N}_{4} \mathrm{O}_{2}$ & $\mathrm{C}_{18} \mathrm{H}_{18} \mathrm{~N}_{4} \mathrm{O}_{2}$ \\
\hline Formula weight & 322.36 & 322.36 \\
\hline Wavelength & 0.71073 & 0.71073 \\
\hline Crystal system & Monoclinic & Monoclinic \\
\hline Space group & “P 21/n” & “P 21/n” \\
\hline Unit cell dimensions $(\AA)$ & $\begin{array}{c}a=10.025(2), b=13.356(3) \\
c=11.964(2), \beta=94.19(3)\end{array}$ & $\begin{aligned} a & =10.0026(4), b=3.6580(8) \\
c & =12.0838(7), \beta=93.802(4)\end{aligned}$ \\
\hline Volume $\left(\AA^{3}\right)$ & $1597.6(6)$ & $1647.20(15)$ \\
\hline$Z$ & 4 & 5 \\
\hline Calculated density & 1.340 & 1.484 \\
\hline Absorption coefficient & 0.091 & 0.098 \\
\hline$F(000)$ & 680 & 780 \\
\hline$\theta$ range for data collection $\left({ }^{\circ}\right)$ & $2.29-25.02$ & $2.96-32.37$ \\
\hline Limiting indices $h, k, l$ & $-11 / 11,-15 / 15,-14 / 14$ & $-14 / 14,-18 / 20,-18 / 16$ \\
\hline Refinement method & Full-matrix least-squares on $F^{2}$ & Full-matrix least-squares on $F^{2}$ \\
\hline Final $R 1 / R 2$ indices $[I>2(I)]$ & $R 1=0.0505, w R 2=0.1041$ & $R 1=0.0595, w R 2=0.1660$ \\
\hline$R$ indices (all data) & $R 1=0.0528, w R 2=0.1054$ & $R 1=0.2097, w R 2=0.2105$ \\
\hline
\end{tabular}

1,2-Dibromo ethane ( 0.02 mole) was added to it and stirred for $15 \mathrm{~h}$. Completion of reaction was monitored through TLC. Solvent was removed on a rotary evaporator and residue was extracted in chloroform: water $(1: 1)(3 \times 100 \mathrm{~mL})$. Organic layer was dried with anhydrous sodium sulfate. Compounds were purified by column chromatography $(50 \%$ EtOAc: hexane) leading to crude product as a yellow powder.

Yield. $1.17 \mathrm{~g} \mathrm{(36 \% );}{ }^{1} \mathrm{H}-\mathrm{NMR}\left(\mathrm{CDCl}_{3}\right), \delta 2.40\left(\mathrm{~s}, 6 \mathrm{H}, \mathrm{CH}_{3}\right)$, $\delta 2.63\left(\mathrm{~s}, 6 \mathrm{H}, \mathrm{CH}_{3}\right), \delta 4.45\left(\mathrm{t}, 2 \mathrm{H}, J=6, \mathrm{CH}_{2}\right), \delta 4.72$ $\left(\mathrm{t}, 2 \mathrm{H}, J=6, \mathrm{CH}_{2}\right), \delta 6.06(\mathrm{~s}, 2 \mathrm{H}, \mathrm{ArCH}), \delta \overline{6.69}(\mathrm{~s}, 2 \mathrm{H}$, $\mathrm{ArCH}) .{ }^{13} \mathrm{C}-\mathrm{NMR}\left(\mathrm{CDCl}_{3}\right) \delta 19.94\left(\underline{\mathrm{CH}}_{3}\right), \delta 20.80\left(\underline{\mathrm{CH}}_{3}\right)$, $\delta 21.73\left(\mathrm{CH}_{3}\right), \delta 24.33\left(\mathrm{CH}_{3}\right), \delta 44.54\left(\mathrm{NCH}_{2}\right), \delta 64.37$ $\left(\mathrm{OCH}_{2}\right), \bar{\delta} 93.50$ (ㄷN), 101.27 (ㄷN), $\delta 109.64(\underline{\mathrm{CN}}), 115.04$ $(\underline{\mathrm{CN}}), \delta 115.33$ (Ar- $\underline{\mathrm{CH}}), \delta 118.08$ (Ar- $\underline{\mathrm{CH}}), \delta 151.98\left(\mathrm{CCH}_{3}\right)$, $\delta 154.37\left(\mathrm{CCH}_{3}\right), \overline{15} 8.41\left(\mathrm{CCH}_{3}\right), \delta \overline{160.93}(\underline{\mathrm{CO}}), \bar{\delta} 163.19$ $\left(\mathrm{COCH}_{2}\right)$. IR $(\mathrm{KBr}) \mathrm{cm}^{-1}: 659-848$ ( $\mathrm{CH}$ bending), 1156-1203 (COC, NC stretching), 1410-1595 (C=C stretching), 1650 (CO stretching), 2219 (CN stretching), 2858-2924 $\left(\mathrm{CH}, \mathrm{CH}_{3}\right.$, and ArH stretching). Elemental analysis for $\mathrm{C}_{24} \mathrm{H}_{22} \mathrm{~N}_{4} \mathrm{O}_{2}$ : Calcd. C; $62.42 \%$, H; 5.20\%, N; 16.18\%, found: C; 62.40\%, H; 5.19\%, $\mathrm{N} ; 16.19 \%$; MS (FAB): $m / z: 346(m+2)$.

2.2. Instrumentation. The $\mathrm{X}$-ray diffraction measurements were carried out using a CrysAlis CCD, Oxford diffractometer. The structure was solved by direct methods with the SHELXS-97 program and refined by the full-matrix least squares method on $F^{2}$ data using the SHELXL-97 program. Molecular graphics: ORTEP; software used to prepare material for publication: MERCURY-3.1. FT-IR spectra were recorded on a VARIAN 3100 FT-IR spectrometer, which was evacuated to avoid water and $\mathrm{CO}_{2}$ absorptions, at a $2 \mathrm{~cm}^{-1}$ resolution in $\mathrm{KBr}$. The $1 \mathrm{H}$ and $13 \mathrm{C}$ NMR spectra were recorded on a JEOL AL300 FTNMR spectrometer operating at 300.40 and $75.46 \mathrm{MHz}$ for proton and carbon 13 , respectively. The $1 \mathrm{H}$ and $13 \mathrm{C}$ chemical shifts were measured $\mathrm{CDCl}_{3}$ solution relative to TMS. The details of the data collection and final refinement parameters are listed in Table 1 and in the supplementary Material available online at http://dx.doi.org/10.1155/2013/309710.

\section{Results and Discussion}

Freshly synthesized 2-[2-(3-cyano-4,6-dimethyl-2-oxo2H-pyridin-1-yl)-ethoxy]-4,6-dimethyl-nicotinonitrile was recrystallized in two different mixtures of solvent. Using mixture of Ethyl acetate-n-hexane $(9: 1)$ solvent, hexagonal crystals of pale pink color was obtained after 2 days at room temperature. However, recrystallization from a mixture of $(1: 1)$ chloroform- $n$-hexane was attempted, resulting in the appearance of light yellow, prismatic crystals (1b), at a temperature of $-5^{\circ} \mathrm{C}$ (refrigerated).

Crystal structure of the 1st polymorph (1a) and 2nd polymorph (1b) is shown in ORTEP diagram in Figure 1, respectively.

Weak aromatic interaction $(\mathrm{CH} \cdots \mathrm{N}, \mathrm{CH} \cdots \pi$, and $\mathrm{CH}$... O interaction) plays an important role in occupying both the polymorphs conformation. A detailed list of their bond lengths and bond angles are summarized in Table 2.

Intermolecular $\mathrm{CH} \cdots \mathrm{N}\left(2.573 \AA, 131.53^{\circ}\right)$ and $\mathrm{CH} \cdots \mathrm{O}$ $\left(2.425 \AA, 174.68^{\circ}\right)$ interaction stabilized the network of $\mathbf{1 a}$ in a symmetrical manner. However, these interactions are absent in polymorph $\mathbf{1 b}$. The major difference observed in the packing diagram of both the polymorphs (Figure 2) is that intermolecular $\pi-\pi$ interaction present between centroid (C13C14C15N3C11C12) and centroid (C4C3C2C1N1C5) of heteroaromatic ring in $\mathbf{1 b}$ is crystallized more closely while 


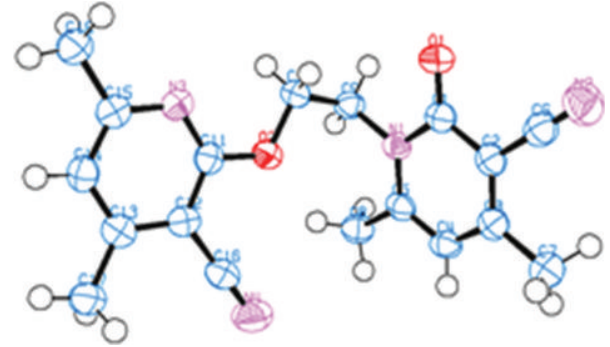

(1a)

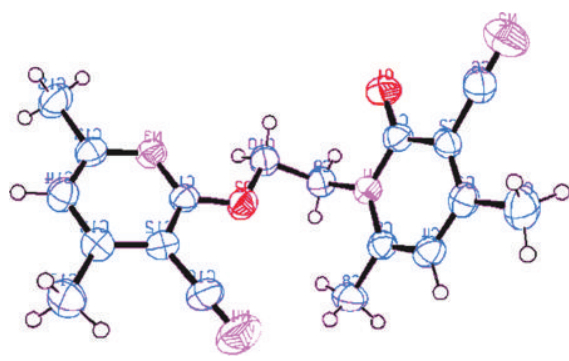

(1b)

FIGURE 1: ORTEP diagram of polymorphs.

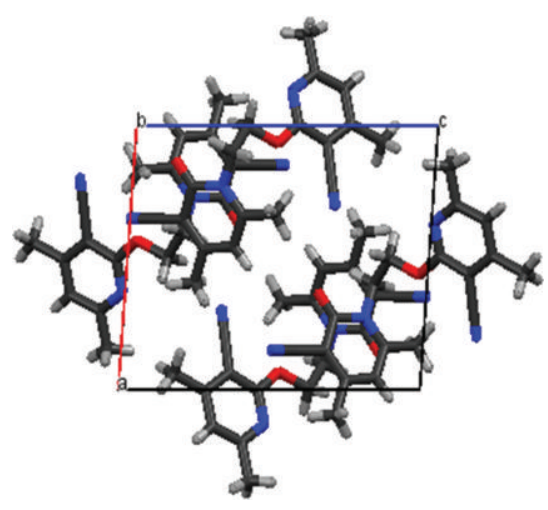

(1a)

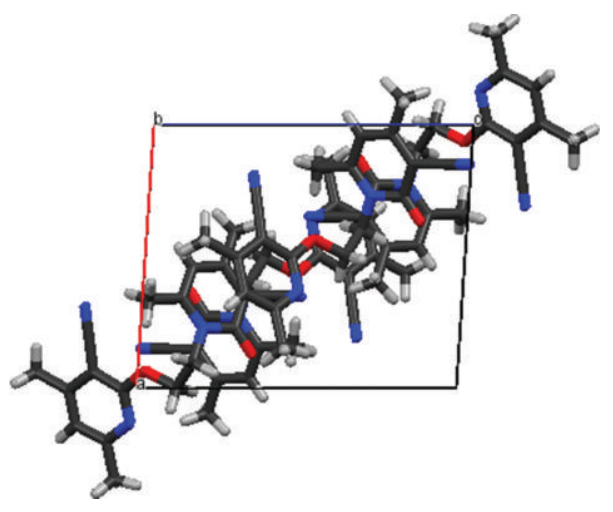

(1b)

Figure 2: Packing diagram of 1st and 2nd polymorph along $b$-axis.

TABLE 2: Intramolecular hydrogen: bonding geometry ( $\AA$ and deg) for $\mathbf{1 a}$ and $\mathbf{1 b}$.

\begin{tabular}{|c|c|c|c|c|c|c|c|c|}
\hline \multirow{2}{*}{$\mathrm{D}-\mathrm{H} \cdots \mathrm{A}$} & \multicolumn{4}{|c|}{ 1a } & \multicolumn{4}{|c|}{$\mathbf{l b}$} \\
\hline & $d(\mathrm{D}-\mathrm{H})$ & $d(\mathrm{H} \cdots \mathrm{A})$ & $d(\mathrm{D} \cdots \mathrm{A})$ & $<(\mathrm{DHA})$ & $d(\mathrm{D}-\mathrm{H})$ & $d(\mathrm{H} \cdots \mathrm{A})$ & $d(\mathrm{D} \cdots \mathrm{A})$ & $<(\mathrm{DHA})$ \\
\hline $\mathrm{CH}_{8 \mathrm{C}} \cdots \mathrm{N} 4$ & 0.980 & 2.915 & 3.496 & 118.96 & 0.959 & 2.664 & 3.544 & 152.32 \\
\hline $\mathrm{CH}_{8 \mathrm{C}} \cdots \mathrm{O} 2$ & 0.980 & 2.489 & 3.237 & 132.93 & - & - & - & - \\
\hline $\mathrm{CH}_{10 \mathrm{~A}} \cdots \mathrm{O} 1$ & 0.990 & 2.660 & 3.145 & 110.36 & - & - & - & - \\
\hline $\mathrm{CH}_{10 \mathrm{~B}} \cdots \mathrm{O} 1$ & - & - & - & - & 0.970 & 2.671 & 3.144 & 110.38 \\
\hline $\mathrm{CH}_{10 \mathrm{~B}} \cdots \mathrm{N} 3$ & 0.990 & 2.564 & 2.713 & 87.82 & 0.970 & 2.770 & 2.700 & 75.75 \\
\hline $\mathrm{CH}_{10 \mathrm{~A}} \cdots \mathrm{N} 3$ & 0.990 & 2.799 & 2.713 & 74.77 & 0.970 & 2.554 & 2.700 & 88.00 \\
\hline $\mathrm{CH}_{8 \mathrm{C}} \cdots \pi(\mathrm{C} 16-\mathrm{N} 4)$ & 0.980 & 2.912 & 3.607 & 128.73 & 0.959 & 2.851 & 3.654 & 141.84 \\
\hline
\end{tabular}

in the case of $\mathbf{l a}$ aromatic $\pi-\pi$ interaction is completely absent and packing of this polymorph stabilized by $\mathrm{CH} \cdots \pi$ interaction (Figure 3).

Both polymorphs are showing roughness in their morphology due to the formation of zigzag sheets via weak interactions. In other words the crystal packing of molecules seems to achieve maximum crystal density. In the packing of the 1st polymorph $\mathbf{l a}$, due to $\mathrm{CH} \cdots \mathrm{O}$ and $\mathrm{CH} \cdots \pi$ (pibond of $\mathrm{CN}$ group) interaction, the molecules linked together and formed a cavity. However, in the case of $\mathbf{1 b}$ the $\pi \cdots \pi$ and $\mathrm{CH} \cdots \pi$ (pi-bond of $\mathrm{CN}$ group) interaction joined the molecules together in packing more tightly and a cavity appears. Presence of different sizes of cavities indicates that both the polymorphs can be used as a host for the different guest molecules. Such kinds of molecular systems will be helpful in many biological systems. Details of intermolecular weak interaction are given in Table 3.

Docking Studies of Synthesized Compound. Firstly, all bound waters, ligands, and cofactors were removed from the proteins. The macromolecule was checked for polar hydrogen; torsion bonds of the inhibitors were selected and defined. Gasteiger charges were computed and the AutoDock atom types were defined using AutoDock 4.2, graphical user interface of AutoDock supplied by MGL Tools [30]. The Lamarckian genetic algorithm (LGA), which is considered one of the best docking methods available in AutoDock [31, 32], was employed. This algorithm yields superior docking performance compared to simulated annealing or the simple genetic algorithm and the other search algorithms available 


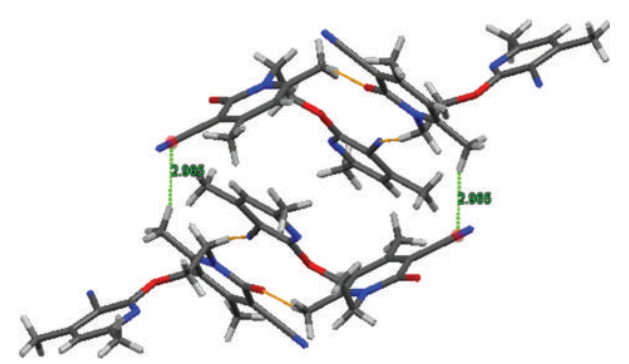

(1a)

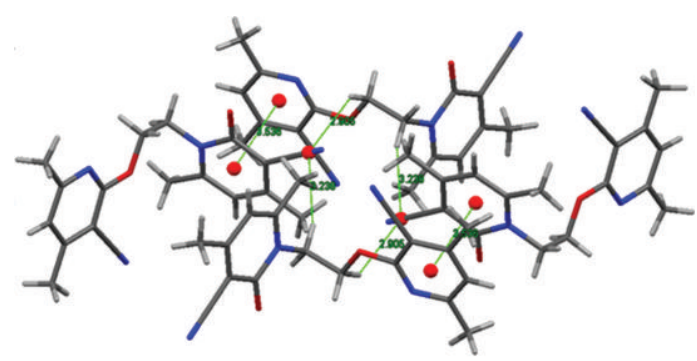

(1b)

FIgURE 3: Packing of crystal shows its geometry and interactions in (1a) and (1b) polymorph.
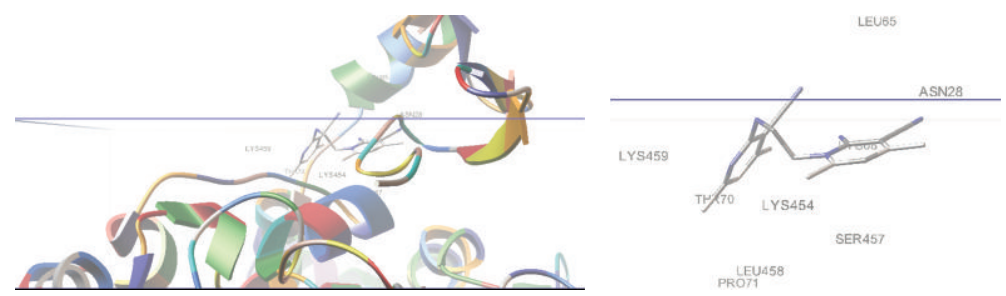

(1a)
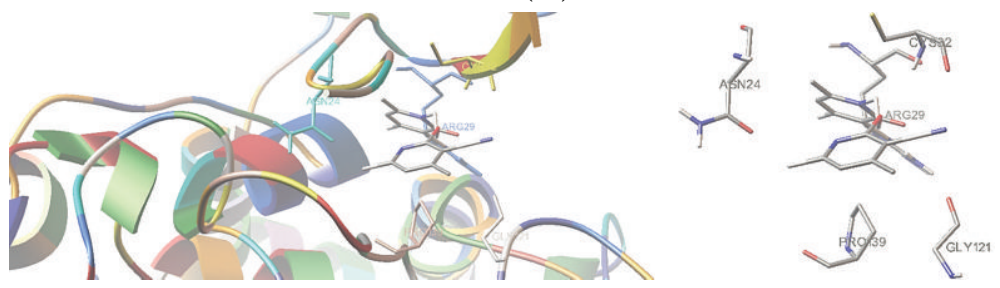

(1b)

FIGURE 4: Docking analysis of both polymorphs.

TABLE 3: Intermolecular hydrogen: bonding geometry ( $\AA$ and $\operatorname{deg})$ for $\mathbf{1 a}$ and $\mathbf{1 b}$.

\begin{tabular}{|c|c|c|c|c|c|c|c|c|}
\hline \multirow{2}{*}{$\mathrm{D}-\mathrm{H} \cdots \mathrm{A}$} & \multicolumn{4}{|c|}{ 1a } & \multicolumn{4}{|c|}{$\mathbf{l b}$} \\
\hline & $d(\mathrm{D}-\mathrm{H})$ & $d(\mathrm{H} \cdots \mathrm{A})$ & $d(\mathrm{D} \cdots \mathrm{A})$ & $<(\mathrm{DHA})$ & $d(\mathrm{D}-\mathrm{H})$ & $d(\mathrm{H} \cdots \mathrm{A})$ & $d(\mathrm{D} \cdots \mathrm{A})$ & $<(\mathrm{DHA})$ \\
\hline $\mathrm{CH} \cdots \mathrm{O}$ & 0.980 & 2.425 & 3.402 & 174.68 & - & - & - & - \\
\hline $\mathrm{CH} \cdots \mathrm{N}$ & 0.990 & 2.573 & 3.313 & 131.53 & - & - & - & - \\
\hline \multirow{2}{*}{$\mathrm{CH} \cdots \pi(\mathrm{C} \equiv \mathrm{N})$} & 0.980 & 2.965 & 3.837 & 148.86 & 0.970 & 2.906 & 3.635 & 132.81 \\
\hline & - & - & - & - & 0.970 & 3.238 & 4.135 & 154.55 \\
\hline$\pi-\pi$ & - & - & - & - & - & 3.536 & - & - \\
\hline
\end{tabular}

in AutoDock 4.2. Secondly, the three-dimensional grid boxes were created by AutoGrid algorithm to evaluate the binding energies on the macromolecule coordinates. The grid maps representing the intact ligand in the actual docking target site were calculated with AutoGrid (part of the AutoDock package). Eventually cubic grids encompassed the binding site where the intact ligand was embedded. Finally, AutoDock was used to calculate the binding-free energy of a given inhibitor conformation in the macromolecular structure while the probable structure inaccuracies were ignored in the calculations. The search was extended over the whole receptor protein used as blind docking.
The ability of compound $\mathbf{l a - b}$ to interact with the COX2 was further assessed by in silico studies with AutoDock (Figure 4). Results indicate that polymorph $\mathbf{1 b}$ shows a better binding effect with COX-2 compared with standard (Nimesulide) than $\mathbf{1 a}$ (Table 4). It seems that $\mathbf{1 b}$ can further be used as anti-inflammatory drug.

\section{Conclusion}

Weak interactions play an important role in stabilizing the structure of both polymorphs due to which they have different crystal packing. The presence of different sizes of cavities, 
TABLE 4: Compounds docking scores compared with indomethacin.

\begin{tabular}{lc}
\hline Compound no. & Docking score \\
\hline $\mathbf{l a}$ & -7.36 \\
$\mathbf{l b}$ & -7.63 \\
Nimesulide & -7.59 \\
\hline
\end{tabular}

formed via such weak interactions, plays a crucial role in their biological activity. Polymorph $\mathbf{1 b}$ has more binding affinity with COX-2 than polymorph 1a. Polymorph $\mathbf{1 b}$ can further be explored for anti-inflammatory activity.

\section{Acknowledgments}

The authors thank UGC India Grant no. 37-54/2009 (SR) for financial assistance of the work. The first author gracefully acknowledges CSIR, New Delhi, India, for CSIR-RA fellowship. Department of Chemistry, Banaras Hindu University, Varanasi, India, and Institute of Pharmaceutical Sciences, Guru Ghasidas Vishwavidyalya (a central university), Bilaspur, Chhattisgarh, India, is acknowledged for departmental facilities.

\section{References}

[1] G. R. Desiraju, "Supramolecular cynthons in crystal engineering-a neworganic synthesis," Angewandte Chemie International Edition, vol. 34, no. 21, pp. 2311-2327, 1995.

[2] R. Boistelle, "Concepts de la crystallisation en solution," in Actualites Nephrologiques, pp. 159-202, Flammarion Medecine Sciences, Paris, France, 1985.

[3] A. R. Choudhury, K. Islam, M. T. Kirchner, G. Mehta, and T. N. G. Row, "In situ cryocrystallization of diphenyl ether: C$\mathrm{H} \cdots \pi$ mediated polymorphic forms," Journal of the American Chemical Society, vol. 126, no. 39, pp. 12274-12275, 2004.

[4] D. W. Jones and T. Borowiak, "Introduction: organic crystal chemistry XI," Journal of Molecular Structure, vol. 647, no. 1-3, pp. 3-7, 2003.

[5] J. A. Zerkowski, J. C. MacDonald, and G. M. Whitesides, "Polymorphic packing arrangements in a class of engineered organic crystals," Chemistry of Materials, vol. 9, no. 9, pp. 19331941, 1997.

[6] P. Munshi, K. N. Venugopala, B. S. Jayashree, and T. N. Guru Row, "Concomitant polymorphism in 3-acetylcoumarin: role of weak C-H $\cdots \mathrm{O}$ and C-H. $\cdots \pi$ interactions," Crystal Growth \& Design, vol. 4, no. 6, pp. 1105-1107, 2004.

[7] R. J. Davey, N. Blagden, G. D. Potts, and R. Docherty, "Polymorphism in molecular crystals: stabilization of a metastable form by conformational mimicry," Journal of the American Chemical Society, vol. 119, no. 7, pp. 1767-1772, 1997.

[8] J. Bernstein, R. J. Davey, and J.-O. Henck, "Concomitant polymorphs," Angewandte Chemie International Edition, vol. 38, no. 23, pp. 3440-3461, 1999.

[9] P. Vishweshwar, A. Nangia, and V. M. Lynch, "Cooperative assistance in a very short $\mathrm{O}-\mathrm{H} \cdots \mathrm{O}$, hydrogen bond. Low-temperature X-ray crystal structures of 2,3,5,6-pyrazinetetracarboxylic and related acids," Chemical Communications, no. 2, pp. 179-180, 2001.
[10] J. P. M. van Duynhoven, R. G. Janssen, W. Verboom et al., "Control of calix[6] arene conformations by self-inclusion of 1,3,5-tri-O-alkyl substituents: synthesis and NMR studies," Journal of the American Chemical Society, vol. 116, no. 13, pp. 5814-5822, 1994.

[11] S. Paliwal, S. Geib, and C. S. Wilcox, "Molecular torsion balance for weak molecular recognition forces. Effects of "tilted-T" edge-to-face aromatic interactions on conformational selection and solid-state structure," Journal of the American Chemical Society, vol. 116, no. 10, pp. 4497-4498, 1994.

[12] R. Dubey and D. Lim, "Weak interactions: a versatile role in aromatic compounds," Current Organic Chemistry, vol. 15, no. 12, pp. 2072-2081, 2011.

[13] E.-I. Kim, S. Paliwal, and C. S. Wilcox, "Measurements of molecular electrostatic field effects in edge-to-face aromatic interactions and $\mathrm{CH}-\pi$ interactions with implications for protein folding and molecular recognition," Journal of the American Chemical Society, vol. 120, no. 43, pp. 11192-11193, 1998.

[14] M. Matsugi, K. Itoh, M. Nojima, Y. Hagimoto, and Y. Kita, "Determination of absolute configuration of trans-2arylcyclohexanols using remarkable aryl-induced ${ }^{1} \mathrm{H}$ NMR shifts in diastereomeric derivatives," Tetrahedron Letters, vol. 42, no. 39, pp. 6903-6905, 2001.

[15] M. Matsugi, K. Itoh, M. Nojima, Y. Hagimoto, and Y. Kita, "A novel determination method of the absolute configuration of 1-aryl-1-alkylalcohols and amines by an intramolecular $\mathrm{CH} / \pi$ shielding effect in ${ }^{1} \mathrm{H}$ NMR," Tetrahedron Letters, vol. 42, no. 45, pp. 8019-8022, 2001.

[16] M. Kitamura, K. Nakano, T. Miki, M. Okada, and R. Noyori, "Stereochemistry of aldols: configuration and conformation of aldols derived from cycloalkanones and aldehydes," Journal of the American Chemical Society, vol. 123, no. 37, pp. 8939-8950, 2001.

[17] M. Matsugi, K. Itoh, M. Nojima, Y. Hagimoto, and Y. Kita, " ${ }^{11} \mathrm{H}$ NMR determination of absolute configuration of 1- or 2-arylsubstituted alcohols and amines by means of their diastereomers: novel separation technique of diastereomeric derivatives of pyridyl alcohols by extraction," Chemistry, vol. 8, no. 24, pp. 5551-5565, 2002.

[18] C. Wolf, L. Pranatharthiharan, and R. B. Ramagosa, "Conformational stability of atropisomeric 1-naphthylcarbinols and 1-(1naphthyl)ethylamines," Tetrahedron Letters, vol. 43, no. 47, pp. 8563-8567, 2002.

[19] A. K. Tewari and R. Dubey, "Emerging trends in molecular recognition: utility of weak aromatic interactions," Bioorganic \& Medicinal Chemistry, vol. 16, no. 1, pp. 126-143, 2008.

[20] V. N. Khrustalev and K. A. Krasnov, "Weak interactions in 1,3-dimethyl-5-arylmethyl-5-cytisylmethylbarbituric acids. Unusually steady intramolecular organic "sandwich" complexes," Journal of Molecular Structure, vol. 828, no. 1-3, pp. 188194, 2007.

[21] G. R. Desiraju, "Crystal gazing: structure prediction and polymorphism," Science, vol. 278, no. 5337, pp. 404-405, 1997.

[22] B. R. Sreekanth, P. Vishweshwar, and K. Vyas, "Supramolecular synthon polymorphism in 2:1 co-crystal of 4-hydroxybenzoic acid and 2,3,5,6-tetramethylpyrazine," Chemical Communications, no. 23, pp. 2375-2377, 2007.

[23] P. Hobza and Z. Havlas, "Blue-shifting hydrogen bonds," Chemical Reviews, vol. 100, no. 11, pp. 4253-4264, 2000.

[24] M. Nishio, "CH/ $\pi$ hydrogen bonds in crystals," CrystEngComm, vol. 6, pp. 130-158, 2004. 
[25] G. R. Desiraju, "C-H.. O and other weak hydrogen bonds. From crystal engineering to virtual screening ", Chemical Communications, pp. 2995-3003, 2005.

[26] M. R. Hauser, L. Zhakarov, K. M. Doxsee, and T. Li, "Polymorphism of a simple organic amide," Crystal Growth and Design, vol. 8, no. 12, pp. 4428-4431, 2008.

[27] J. D. Dunitz and J. Bernstein, "Disappearing polymorphs," Accounts of Chemical Research, vol. 28, no. 4, pp. 193-200, 1995.

[28] J.-O. Henck, J. Bernstein, A. Ellern, and R. Boese, "Disappearing and reappearing polymorphs. The benzocaine: picric acid system," Journal of the American Chemical Society, vol. 123, no. 9, pp. 1834-1841, 2001.

[29] A. K. Tewari, V. P. Singh, R. Dubey, C. Puerta, P. Valerga, and R. Verma, "Importance of weak interactions in developing 1,3-bis(4,6-dimethyl- ${ }^{1} \mathrm{H}$ - nicotinonitrile-1-yl)1,3-dioxy propane polymorphs," Spectrochimica Acta A, vol. 79, no. 5, pp. 12671275, 2011.

[30] M. F. Sanner, "Python: a programming language for software integration and development," Journal of Molecular Graphics and Modelling, vol. 17, no. 1, pp. 57-61, 1999.

[31] R. Huey, G. M. Morris, A. J. Olson, and D. S. Goodsell, "Software news and update a semiempirical free energy force field with charge-based desolvation," Journal of Computational Chemistry, vol. 28, no. 6, pp. 1145-1152, 2007.

[32] G. M. Morris, D. S. Goodsell, R. S. Halliday et al., "Automated docking using a Lamarckian genetic algorithm and an empirical binding free energy function," Journal of Computational Chemistry, vol. 19, no. 14, pp. 1639-1662, 1998. 

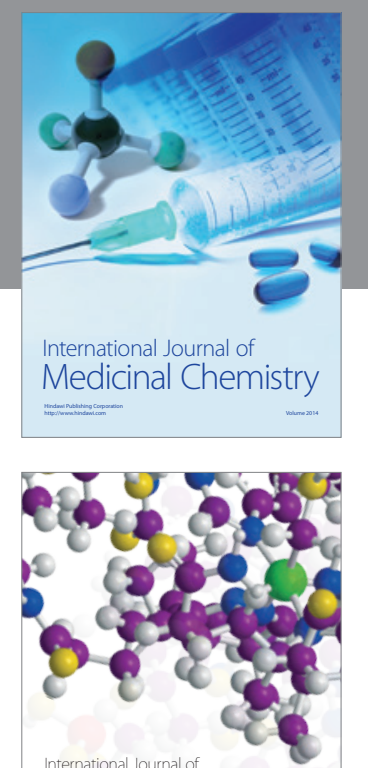

\section{Carbohydrate} Chemistry

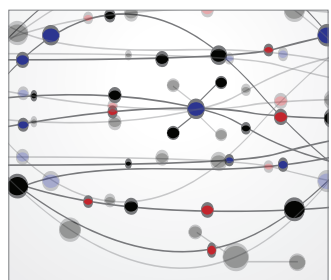

The Scientific World Journal
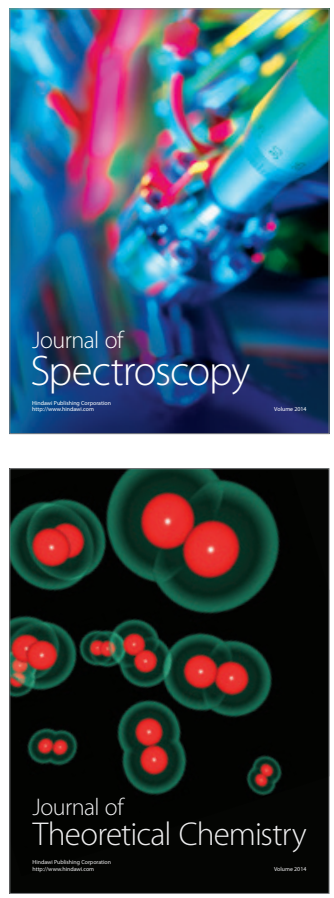
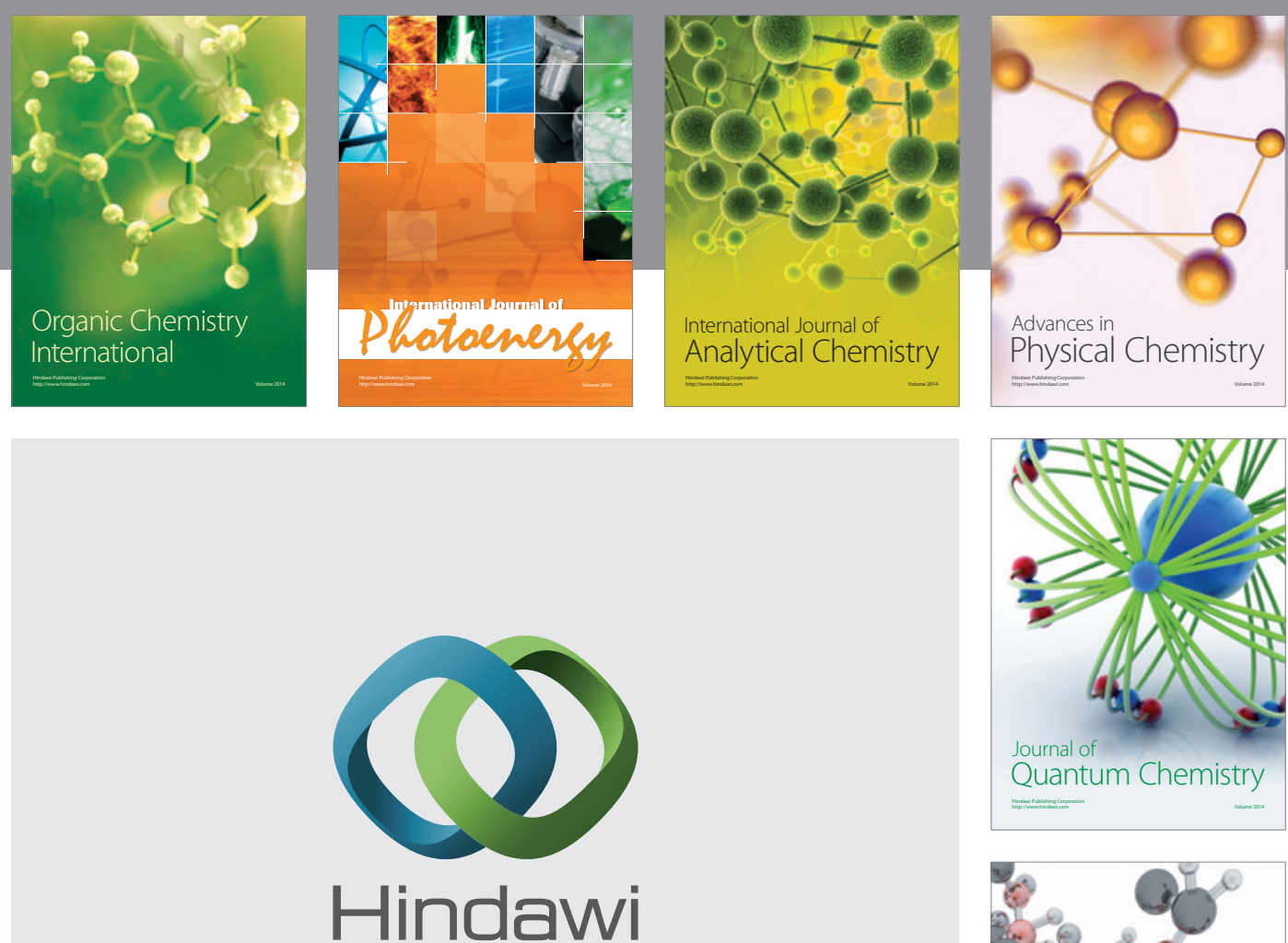

Submit your manuscripts at

http://www.hindawi.com

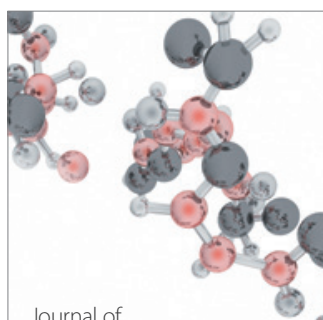

Analytical Methods

in Chemistry

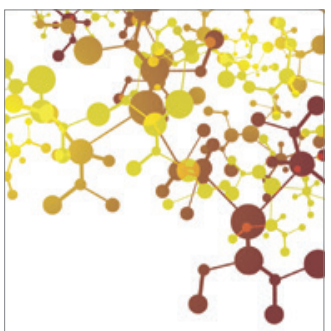

Journal of

Applied Chemistry

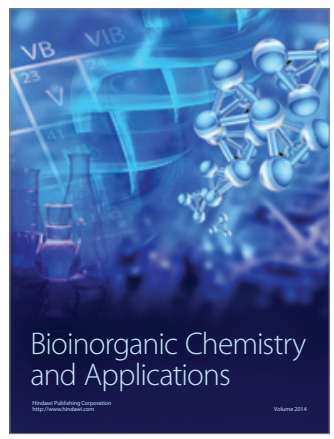

Inorganic Chemistry
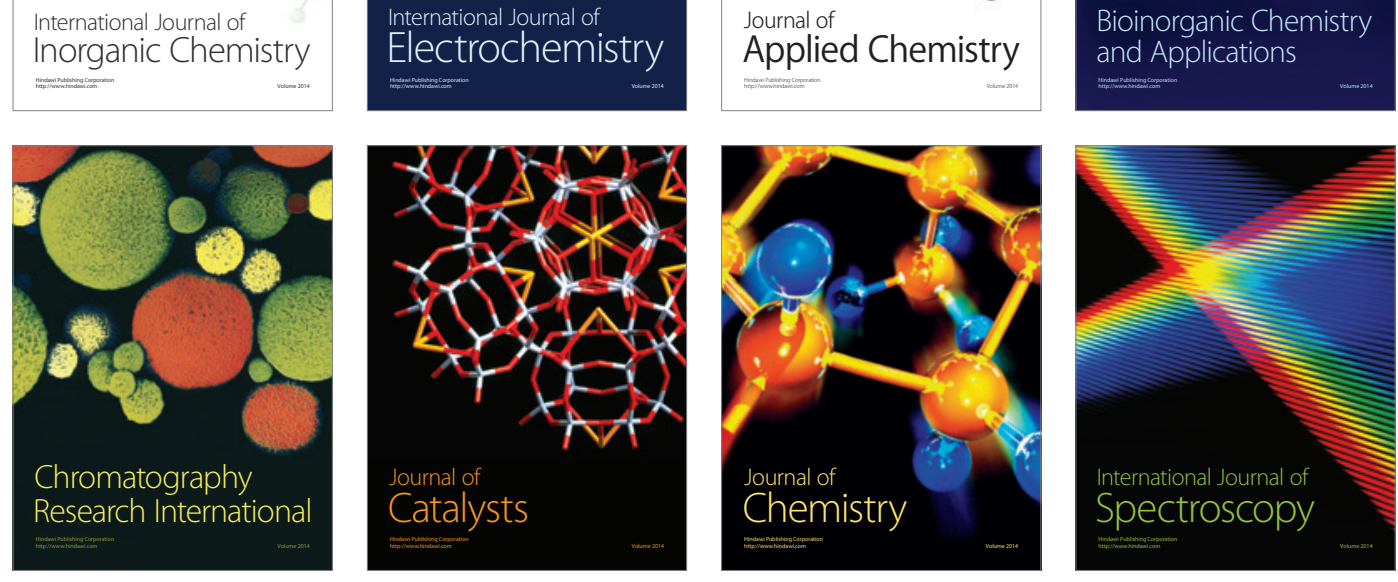